\title{
A qualidade da investigação em ciências do desporto e áreas afins: alguns conselhos úteis para a submissão bem-sucedida dos manuscritos
}

\author{
The quality of the research in sport science and related scientific fields: \\ some advices for a successful manuscript submission
}

Tiago M. Barbosa ${ }^{1 *}$

Quase um ano após o novo corpo editorial da Motricidade ter tomado posse, é tempo de fazer um breve balanço. Temos de agradecer a todos os autores que depositam confiança na revista, submetendo manuscritos ao longo dos últimos meses. O número de submissões é particularmente estável sendo os tópicos propostos bastante diversos, como é nossa intenção. O número de submissões em língua inglesa, apesar de ser obrigatório apenas a partir de Janeiro de 2016, tem vindo a aumentar de forma substancial.

Como tinha sido publicado num dos editoriais anteriores, o processo de revisão passou a ser mais centrado no desenho experimental, na explicitação do problema científico em análise, dos objetivos definidos e das hipóteses a testar. Antes do envio dos manuscritos para revisão externa estes são analisados pelo corpo editorial. Não podemos escamotear que a percentagem de rejeições ainda antes do envio dos trabalhos para revisão pelos pares não é negligenciável.

Há três motivos principais para a rejeição dos trabalhos nesta fase inicial. O primeiro é o manuscrito submetido não estar de acordo com as regras de redação da Motricidade. Os autores são convidados a ler atentamente as regras de redação e verificarem se estas são vertidas no manuscrito, antes de o carregarem no sistema.

O segundo motivo está relacionado com a prioridade na potencial publicação dos trabalhos. Sem ser exaustivo, existem quatro níveis de pesquisa ou análise: a) a descritiva; b) a correlacional; c) a causal; d) a bibliográfica. Considerem-se estes níveis na forma de uma pirâmide, onde a pesquisa descritiva é a base, a pesquisa bibliográfica é o topo, ficando as pesquisas correlacional e causal no meio. Estudos meramente descritivos são o nível inferior do conhecimento científico, pelo que a sua prioridade será menor do que as restantes formas de pesquisa. Segue-se a análise correlacional num segundo nível porque apenas permite estabelecer um nível de associação entre variáveis, sem que qualquer nexo de causalidade seja reportado. Uma área de crescente interesse dentro da pesquisa causal são as análises confirmatórias, que se encontram um nível acima das análises exploratórias. Por fim temos as revisões da literatura. Revisões do tipo qualitativa são acessíveis a autores com alguma produção de trabalho empírico na área e/ou tópico em causa com reconhecimento pelos pares na forma de citações (i.e. índex-H). Para os restantes, é possível a submissão de revisões sistemáticas ou meta-análises.

A terceira razão para a rejeição precoce das submissões fundamenta-se no desenho experimental. Obviamente esse desenho depende da área científica e do tema, daí que os editores-associados, com base na sua área de especialidade, tem um papel determinante na revisão interna. Infelizmente, num editorial não é possível abordar todas as áreas cobertas pela Motricidade. Todavia, o número de submissões relatando intervenções nas áreas da saúde, da aptidão ou exercício físico para diversos tipos de populações é significativo. Para esses, o conselho é terem como referência algumas escalas e índices existentes na

\footnotetext{
${ }^{1}$ Editor Chefe da Revista Motricidade; Physical Education \& Sports Science Academic Group, National Institute of Education, Nanyang Technological University

*NIE5-03-31, 1 Nanyang Walk, Singapore; Email: editor.in.chief@revistamotricidade.com
} 
literatura para a avaliação da qualidade dos trabalhos publicados.

A escala PEDro, o quality índex de Downs e Black ou a escala Jadad são alguns exemplos. Nenhuma escala é perfeita, mas no cômputo geral, os autores que desejem submeter trabalhos nestas áreas podem-se guiar por elas, usando-as como listas de verificação. Estas escalas poderão ser utilizadas para verificar se algumas das questões relacionadas com o desenho experimental, a validade interna ou externa, a potência das estatísticas descritas e outros elementos que são importantes de relatar não foram esquecidos ou negligenciados. Curiosamente, encontram-se na internet bases de dados em que se pode efetuar a pesquisa pelo nome dos autores, tópico, título ou outros meta-dados de artigos já publicados e em poucos segundos se obtém a classificação atribuída, com base nos critérios de uma determinada escala.

Se os trabalhos estiverem dentro das condições enunciadas atrás, são enviados para revisão externa pelos pares. E neste domínio, o nosso profundo agradecimento àqueles que despendem o seu precioso tempo efetuando a análise crítica e detalhada dos trabalhos submetidos. Com efeito, a qualidade e a celeridade do processo de revisão de um trabalho é diretamente proporcional ao empenho pessoal de cada revisor ao colaborar com a Motricidade. 